\title{
VOZES CATÓLICAS NO CONGRESSO NACIONAL: ABORTO, DEFESA DA VIDA
}

\author{
MYRIAM ALDANA \\ Universidade Comunitária Regional de Chapecó
}

\begin{abstract}
Resumo: Serão analisados neste ensaio alguns dos debates em torno da temática do aborto que ocorreram no Congresso Nacional com a ocasião da Proposta de Emenda Constitucional - central da discussão foi a defesa da vida. Serão identificados os blocos discursivos que apresentam posições contrárias e favoráveis à interrupção da gravidez, os princípios religiosos ou determinismo biológico em que essas posições estão ancoradas e as formas como esses discursos permanecem. Ainda são levantadas as diferentes compreensões do que é vida, decorrentes dos argumentos utilizados nesses discursos, os quais estão alinhados com os posicionamentos da Igreja Católica e do Movimento Feminista, atores sociais protagonistas desse embate.
\end{abstract}

Palavras-chave: aborto; discurso católico; defesa da vida.

O aborto, um dos eventos da vida reprodutiva das mulheres, aparece na pauta dos debates mais polêmicos das últimas décadas, tanto em nível nacional como internacional; mas no presente ano de 2008 essa questão assume uma posição relevante no Brasil, a partir do lançamento da Campanha da Fraternidade da Igreja Católica com o tema "A defesa da vida", que faz emergir controvérsias políticas e jurídicas de acordo com as diversas compreensões do que significa defender a vida.

Serão analisados neste ensaio alguns dos debates em torno dessa temática que ocorreram no Congresso Nacional com a ocasião da Proposta de Emenda Constitucional PEC25/95' da autoria do deputado Severino Cavalcanti (PPB/PE), em que precisamente o pomo central da discussão foi a defesa da vida. A proposta que pretendia mudar a redação do artigo $5^{\circ}$ da Constituição Federal, acrescentando ao "direito à vida" a expressão "desde a concepção", foi um tema que desde 1987, no processo de elaboração da nova Constituição Nacional, já se constituía no núcleo de conflito. Sinalizarei o embate político

Copyright (C) 2008 by Revista Estudos Feministas.

' Este levantamento sobre os argumentos apresentados nos debates do Congresso Nacional faz parte de um trabalho mais amplo sobre a tramitação de projetos de lei relativos aos direitos sexuais e reprodutivos que tramitaram na década de 90 . 
entre a lgreja Católica e o Movimento Feminista ${ }^{2}$ como atores sociais que têm visões diferentes e até contraditórias sobre esse assunto: enquanto para a lgreja Católica trata-se de questões éticas e morais, para as feministas são questões de direitos.

Enquanto para aqueles o aborto continua sendo encarado somente como problema ético, um crime contra a vida (e a vida de um inocente indefeso), para estes é visto como um dos direitos reprodutivos, com o qual se determina o grau de domínio que a mulher pode ter sobre o seu próprio corpo. Conseqüentemente, o aborto passaria a ser uma questão de saúde da mulher e de saúde pública. Essa duplicidade de visões tem marcado o debate que se trava no Congresso Nacional - duplicidade que se estende, via de regra, para a maioria dos temas que dizem respeito à sexualidade e à reprodução humana.

O aborto no contexto dos direitos sexuais e direitos reprodutivos é considerado pelas feministas como último recurso diante de uma gravidez indesejada; por isso a importância dada à educação sexual, à orientação médica, ao acesso aos métodos contraceptivos tanto para homens quanto para mulheres na perspectiva de evitá-lo. Porém, é também considerado como um direito: poder realizar a interrupção voluntária da gravidez em condições humanas e seguras sem comprometer a saúde das mulheres. É uma questão de cidadania e de justiça social, uma vez que a autonomia das mulheres para decidir diante de uma gravidez indesejada deve ser respeitada, merecendo, igualmente, ser uma possibilidade aberta a todas as mulheres, mediante o acesso efetivo a esse serviço de saúde. ${ }^{3}$

A luta entre essas duas linhas de pensamento e de orientação política continuaria no Congresso Nacional durante toda a década de 90, quando foi grande o número de projetos de lei relativos à reprodução e à sexualidade nele tramitando. Somente na primeira legislatura parlamentar (1991-1995) "foram apresentadas dezoito proposições". ${ }^{4}$

Atualmente, continuam tramitando no Congresso Nacional projetos sobre o aborto legal, assim como outras propostas que pretendem estender os permissivos para interrupção da gravidez nos casos de malformação fetal e que causem risco para a saúde física ou psíquica da gestante, e proposições que dispõem sobre a descriminalização e a legalização do aborto. As forças contrárias, ligadas à Igreja Católica e a algumas Igrejas Evangélicas, também apresentaram propostas de projetos, tais como 'o dia do nascituro', a transformação de toda e qualquer forma de aborto em crime hediondo, a adoção da pena de reclusão nos casos de aborto provocado em razão de anomalia fetal, o atendimento e o apoio especial, inclusive financeiro, às mulheres que levem até o final a gravidez resultante de estupro, recebendo um salário mínimo até que a criança complete os 18 anos. ${ }^{5}$

Vejamos então alguns dos argumentos apresentados no Congresso Nacional pelos participantes nos debates sobre aborto nas Audiências Públicas. O conjunto de idéias que conformam o bloco discursivo contrário à interrupção da gravidez foi extraído dos depoimentos expressos pelos participantes da Audiência Pública acima citada, os quais enfatizam argumentos baseados na lei natural, na verdade da fé católica, que professa que a vida é dom de Deus, e na defesa dos direitos do feto. ${ }^{6}$

\footnotetext{
${ }^{2}$ Isto não significa que ignoremos a atuação de outros atores, como o Movimento GLTTB, a BemFam, a Federação Brasileira das Sociedades de Ginecologia e Obstetrícia - FEBRASGO, o próprio Movimento Feminista e o Movimento de Mulheres, entre outros, os quais, com maior ou menor ênfase, entram na cena política deste debate em diferentes momentos, dependendo da conjuntura e dos interesses.

${ }^{3}$ Almira RODRIGUES, 2000.

${ }^{4}$ Maria Isabel Baltar ROCHA, 1996, p. 385.

${ }^{5}$ CFÊMEA, n. 154, nov./dez. 2007.

${ }^{6}$ Os depoimentos que formam o discurso contrário à interrupção da gravidez foram escolhidos entre aqueles que expressavam um certo consenso dos que se manifestaram. Esse consenso foi determinado pela maior freqüência com que as profissões de fé católica apareciam. Cada parágrafo está conformado por idéias de dois ou mais participantes.
} 
A vida, um bem inalienável, não é propriedade particular de ninguém. A vida pertence a Deus. E nós seres humanos não temos o direito de tirar a vida de quem quer que seja. No caso do estupro, por mais privilegiado que seja o direito da mulher, ela não tem o direito de pôr fim a uma vida. No caso dos nascituros que pelas leis da natureza ao estar no seio materno, não podem falar a Igreja assume sua voz para a defesa de suas vidas, a vida dos inocentes. A Igreja defende a vida desde a sua concepção. A vida do feto que está no corpo da mãe, mesmo ainda embrião, não se confunde com o seu corpo. É outra vida que está sob a guarda da mãe. Cabe-lhe somente defendê-la. Cabe também ao poder público o dever de defendê-la.

A tentativa de equalização do direito à vida por parte de ambos, mãe e feto, por estar fundamentada numa concepção essencialista e meramente biológica de vida humana, ignora os aspectos subjetivos, culturais, sociais e políticos da mãe, ou seja, reconhece na vida humana apenas o aspecto da sobrevivência biológica, ignorando que ela tem uma dimensão subjetiva própria de cada ser humano, um modo peculiar de dar-lhe sentido cultural e socialmente. Cada indivíduo no seu grupo social desempenha papéis, criando uma "imagem" própria e sendo reconhecido por suas funções, pelo significado que tem para a comunidade. Politicamente, cada indivíduo está ligado a uma comunidade maior diante da qual tem direitos e deveres, e com o qual o Estado também assume tarefas por meio de políticas públicas, visando não só a sua sobrevivência mas também a sua qualidade de vida. Ao falarmos em "qualidade de vida" e não só em sobrevivência, estamos introduzindo um critério importante e decisivo na avaliação das condições da vida humana, pois não se trata apenas de defender a vida a qualquer custo, mas que as pessoas, ou seja, os/as cidadãos/ãs tenham condições de usufruir de uma existência realmente "humana". Isso tudo pode e deve ter peso no momento de optar pela continuidade ou não de uma gravidez indesejada, tornando a escolha muito mais humana, moral e socializada. Daí por que não se pode simplesmente igualar o direito à vida na medida em que o peso de duas vidas depende também de todos os critérios acima apontados.

Queremos conscientizar este Plenário de que se trata de uma outra vida, única, incapaz de ser repetida, e nós devemos defendê-la, independentemente de como ela se constitua. Falou-se muito aqui hoje em defesa do direito da mulher, mas esqueceram o direito do feto. O direito da mulher está sendo muito defendido. E quem defenderá o direito do feto, indefeso, na barriga da mãe? Se o Estado não proteger a vida, quem vai protegê-la? ${ }^{8}$

Nesse discurso, aparece na retórica antiaborto a admissão e até mesmo a invocação da entrada do Estado na defesa da vida do nascituro; assim se está reconhecendo a passagem do processo reprodutivo humano para o âmbito "político", para o "espaço público", dando-Ihe outro fórum: o do Direito Positivo. Com isso, coloca-se a questão para a sociedade política, a qual não é confessional, tendo direito de legislar em prol dos/as cidadãos/ãs de qualquer credo religioso ou mesmo dos que não têm religião nenhuma. Na medida em que são estabelecidos direitos e deveres positivos aos cidadãos, é dever do Estado garantir o seu cumprimento. Segundo as análises de Rosalind Petchesky, esses argumentos pretendem evitar a crítica de que defender o feto contradiz o princípio da separação Igreja/Estado, pois supostamente se colocariam argumentos 'científicos' do campo da embriologia e não do campo religioso.

\footnotetext{
${ }^{7}$ Depoimento em Audiência Pública em novembro de 1995 de Dom Cláudio Hummes da CNBB, coordenador da equipe de cursos de noivos da Vila Olímpia, em São Paulo (BRASIL, 1995).

${ }^{8}$ Depoimentos na Comissão Geral do presidente da Ação Familiar de Brasil, deputado Miguel Martini, de Minas Gerais. ${ }^{9}$ Rosalind PETCHESKY, 1990
} 
Essa visão que defende a 'vida do feto' tem receptividade nas análises legais, que argumentam a superioridade do direito à vida sobre outros direitos, a partir de uma definição de vida em termos biológicos abstratos. E quando se contrapõe a vida da mulher versus a vida do feto, esvazia-se o papel da mulher na reprodução. Ao humanizar a vida do feto, por meio da reificação do feto como ser humano, desumaniza-se a vida da mulher em virtude de coisificá-la, convertida numa 'incubadora', 'meio ambiente', e na medida em que se reifica exclusivamente como mulher/mãe. ${ }^{10}$

Desde a perspectiva que enfatiza a defesa do feto, dada sua inocência e incapacidade de defesa, sob a qual os argumentos afirmam: "E quem defenderá o direito do feto, indefeso, na barriga da mãe? Se o Estado não proteger a vida, quem vai protegêla?" Podemos concluir que se requer mesmo a intervenção do Estado e a sociedade civil para sua proteção, e, portanto, o corpo das mulheres, especificamente seu útero, será o campo de batalha em que toda a sociedade entra para defendê-lo e cada mulher enfrentará esse exército que a invade para impor-lhe a maternidade e negar-lhe sua capacidade de agente moral com a possibilidade de tomar as decisões sobre sua vida; $e$ o mais grave ainda: colocando-a como criminosa, assassina de um inocente. Retomando as análises de Rosalind Petchesky sobre a discussão dos aspectos morais e éticos do aborto, ela nos mostra que: "alguém que obrigue uma mulher a levar uma gravidez até o fim e a alimentar um feto que não deseja, é também um assunto de natureza moral ou ética". ${ }^{12}$

Analisando os fundamentos 'imutáveis' que se repetem nas posições contrárias à interrupção da gravidez, constatamos uma simbiose entre esses e os documentos da lgreja Católica. Maria Jose Rosado, ${ }^{13}$ que trabalha 0 conteúdo argumentativo presente nos documentos da Igreja Católica, afirma que a doutrina oficial de Igreja Católica sobre a imoralidade do aborto é clara, taxativa e se propõe como absoluta, apresentando-se em forma de um bloco discursivo, constituindo-se numa espécie de fortaleza doutrinal em torno da sua condenação, sendo o elemento central a defesa da vida proposta como princípio absoluto, imutável e intangível. "O caráter sagrado da vida humana e a condição de pessoa do embrião fundamentam a condenação incondicional do aborto, integrando argumentos de índole religiosa moral e biológica". ${ }^{14}$

As fontes desse discurso se encontram nas Escrituras Sagradas (Bíblia) e nos textos do Magistério Supremo da Igreja, ou seja, do Papa e das Sagradas Congregações do Vaticano, especialmente a da Doutrina da Fé. Ambas as fontes têm para a hierarquia católica o mesmo valor: são absolutas, universalmente válidas, sem necessidade de serem contextualizadas espacial e temporalmente. Por esse seu caráter, poderíamos classificálas na categoria epistemológica de Foucault, "o discurso fundante" ou as "metanarrativas": "fórmulas, textos conjuntos ritualizados de discursos que se narram, conforme circunstâncias bem determinadas [...] os discursos que indefinidamente, para além de sua formulação são ditos, permanecem ditos e estão ainda por dizer". ${ }^{15}$

Por isso é que, nos argumentos dos representantes da hierarquia e dos movimentos católicos que se apresentaram na Audiência Pública sobre a PEC25/95, encontramos a citação freqüente dos documentos oficiais do Magistério Eclesiástico.

\footnotetext{
${ }^{10}$ Alice COLÓN et al., 1997.

${ }^{\prime}$ Depoimentos na Comissão Geral do presidente da Ação Familiar de Brasil, deputado Miguel Martini, de Mina Gerais.

12 PETCHESKY, 1990, p. 31.

${ }^{13}$ Maria José ROSADO e Regina SOARES, 1999.

${ }^{14}$ ROSADO E SOARES, 1999, p. 267.

${ }^{15}$ Michel FOUCAULT, 1971, p. 22.
} 
O discurso fundante, por sua vez, estabelece uma hierarquia de subprodutos que Foucault destaca e os chama de o comentário, a verdade e o conhecimento como algo conatural ao homem. Esses subprodutos aparecem claramente nos argumentos repetitivos da lei natural, da vida sagrada de Deus único dono da vida, entre outros. Analisemos mais detalhadamente esses subprodutos:

\section{a) O comentário}

Tomemos o depoimento de um deputado do Grupo Parlamentar Católico (GPC) na Audiência Pública da PEC25/95, no qual encontramos os mesmos argumentos do discurso coletivo apresentado nas páginas anteriores desse artigo:

Acredito que a vida começa no momento da concepção. Ela se inicia a partir do momento da concepção, e a partir daí ela é inviolável, ou seja, não pode ser tocada. Uma vida não é gerada simplesmente por um homem e uma mulher, mas é um dom de Deus. Com toda certeza, o homem não teria como formar um ser tão perfeito como o ser humano [...]. Acredito que a mulher tem direito sobre seu corpo, mas não tem direito sobre o ser que está sendo gerado dentro dela, porque não é dela, não pertence a ela, não é ser que lhe pertence. Portanto, não pode ser tocado. ${ }^{16}$

Esse exemplo nos mostra o que Foucault chama de comentário, no qual se pode facilmente perceber o desnível entre o texto primeiro e o texto segundo. Em nosso caso, os argumentos utilizados nas diversas audiências seriam os textos segundos. É interessante sinalizar os dois papéis que esse desnível entre os textos desempenha: permite construir (e indefinidamente) novos discursos: "o fato do texto primeiro pairar acima, sua permanência, seu estatuto de discurso é sempre reatualizável". ${ }^{17}$ Seja qual for a apresentação do discurso ou a metodologia empregada, o comentário sempre vai dizer aquilo que estava articulado silenciosamente no texto primeiro. Como diz Foucault: "O novo não está no que é dito, mas no acontecimento da sua volta". ${ }^{18} \mathrm{O}$ comentário nunca poderá superar o texto fundante em sua extensão, compreensão e profundidade.

Porém, por que se faz uso desses textos fundantes? Por que eles servem de fundamento para a defesa de projetos atuais, contextualizados? Por que não se pergunta ou não se questiona sua validade, sua origem? Por que não importa conhecer o processo de como se chegou a essas "verdades primeiras"?

É justamente na natureza desse "discurso primeiro ou fundante" que reside sua força, seu poder: na inquestionabilidade da sua autoridade, no peso de sua tradição, na crença e na fé no "deus" ou no "magistério" que o criou, ditou ou elaborou. Como não se admite buscar, investigar sua origem, não se ousa contestar ou extrapolar seu conteúdo. Aqui a "verdade, a coisa verdadeira" é antes uma questão de poder, de autoridade. É a Verdade ligada intrinsecamente ao Poder. Quem consegue impor uma verdade consegue impor seu poder. Quem faz uso dessa verdade indiretamente está fazendo uso desse mesmo poder. Fazer uso do discurso fundante é invocar o poder desse discurso, é sentir-se partícipe desse poder. É mais ou menos o que nos diz Foucault no seguinte texto: "O discurso não é simplesmente aquilo que traduz as lutas e os sistemas de dominação, mas aquilo pelo que se luta, o poder do que queremos nos apoderar". ${ }^{19}$

\footnotetext{
${ }^{16}$ Deputado membro do Grupo Parlamentar Católico, na Audiência Pública sobre a PEC25, no Congresso Nacional, realizada em 7 de julho de 1995 (BRASIL, 1995).

${ }^{17}$ FOUCAULT, 1996, p. 25.

${ }^{18}$ FOUCAULT, 1996, p. 26.

${ }^{19}$ FOUCAULT, 1971, p. 10.
} 
b) Verdade versus falsidade

Outro aspecto do discurso fundante é sua verdade em contradição com os falsos discursos.

[...] em toda sociedade a produção do discurso é, ao mesmo tempo, controlada, selecionada, organizada e redistribuída por certo número de procedimentos que têm por função conjurar seus poderes e perigos, dominar seu acontecimento aleatório, esquivar sua pesada e temível materialidade.

Dentre esses diversos procedimentos para controlar a produção do discurso "verdadeiro", Foucault aponta a interdição (ou proibição de tocar em certos temas ou tabus, como sexualidade, vida humana etc.), a rejeição (sob a acusação de loucura, de perda da razão, o que desqualifica o sujeito), a exclusão do falso comparado com o verdadeiro. ${ }^{21}$

E nesse processo (de imposição de uma "verdade") o essencial é a busca da verdade, certas ordens de verdade, certos domínios do saber que circulam na nossa sociedade e se impõem a ela, valendo para o domínio da política, para o domínio do comportamento quotidiano e até para a ordem da ciência. ${ }^{22}$

A Associação Pró-Vida, por exemplo, em suas ações preventivas para a defesa da vida contra o aborto elencadas no documento "Os Atentados à Vida e à Família", propõese, especialmente, a divulgar as informações 'verdadeiras', assim expressas:

A propaganda abortista é baseada na mentira. Mentem quando divulgam estatísticas falsas de morte materna pelo aborto clandestino, mentem quando se referem ao aborto dizendo que se vai "esvaziar o conteúdo do útero", mentem quando dizem que o aborto é uma operação simples, mentem quando dizem que há "aborto legal", mentem quando dizem que apenas querem regulamentar os casos de aborto previsto no art. 128 do Código Penal, etc. [...] O trabalho preventivo de defesa da vida se resume em dizer a VERDADE e divulgar essa verdade $[\ldots]^{23}$

Portanto, o essencial é ter o discurso "verdadeiro" ao conhecer a verdade e ao prevenir contra a mentira. O discurso verdadeiro, no caso, está com os seguidores do discurso fundante elaborado ou preservado pelo Magistério Oficial da Igreja Católica. A mentira é o discurso que se opõe a ele. E conhecer a verdade é equivalente a fazer o que é verdadeiro. A preocupação maior se encontra no conhecimento da verdade, não necessariamente na prática. O erro estaria fundamentado no desconhecimento da verdade. E a pessoa que cai nele é culpada, pois tem condições de conhecer a verdade, na medida em que o conhecimento é conatural à natureza humana.

Segundo aparece nas primeiras declarações dos representantes do Magistério Oficial, o conhecimento da verdade revelada, da verdade primeira estaria ao alcance de todo homem, pois essa verdade primeira está ou é a Lei Natural: "Bem antes (desta lei bíblica), ela está inscrita no coração de todo homem como lei natural, e, portanto, vinculada a todos e todos a podem conhecer pela simples luz da razão humana [...]". ${ }^{24}$ Por isso, todos os povos desde sempre a conhecem, ou seja, para as instâncias católicas, o conhecimento da Lei Natural é algo inato, manifestado diretamente à consciência humana, a tal ponto que todo homem pode atingi-lo, tornando-se, então, responsável por sua violação.

\footnotetext{
${ }^{20}$ FOUCAULT, 1971, p. 8.

${ }^{21}$ FOUCAULT, 1971.

${ }^{22}$ FOUCAULT, 1971.

${ }^{23}$ Humberto Leal VIEIRA, 1998, p. 57.

${ }^{24}$ VIEIRA, 1998, p. 59.
} 
Daqui pode provir a convicção da hierarquia católica de se situar como intérprete da vontade divina e sua defensora. Conseqüentemente, pensa que pode impor essa vontade a todos os homens, independentemente de seu credo ou de sua incredulidade religiosa.

Desse ponto de vista discordam inúmeros membros da Igreja e outros grupos que partem de convicções diversas para defender a possibilidade ou o direito à escolha entre levar até o fim ou interromper uma gravidez indesejada.

Na Comissão Geral sobre o projeto de lei relativo ao aborto legal, a coordenadora nacional da ONG Católicas pelo Direito de Decidir deu o seu depoimento desde a perspectiva religiosa, apoiando-se em declarações de bispos e documentos da Igreja Católica, mas divergindo da posição da hierarquia, assim como dos depoimentos religiosos contrários à interrupção da gravidez. Apresentamos partes de seu discurso:

Nas discussões em torno do aborto no Brasil, não é raro que os opositores aos projetos que descriminalizam o aborto e o tornam acessível às mulheres invoquem princípios cristãos para afirmar sua prática como ato homicida e pecaminoso. Muitas vezes essa posição é apresentada como se refletisse o pensamento de todos os membros das Igrejas cristãs. Raramente se faz alusão à diversidade interna e às discussões existentes em torno das proposições de uma moral sexual inspirada em princípios religiosos. Isso é particularmente verdade no caso da Igreja Católica. O próprio Bispo católico canadense D. Raymond John Lahey propôs, no Sínodo das Américas, que agora se realiza em Roma, que a Igreja Católica abra o diálogo com os grupos que defendem os direitos das mulheres de interromperem uma gravidez.

Mesmo atualmente - repito -, existem muitas teólogas e teólogos moralistas católicos que justificam, do ponto de vista religioso, a decisão da mulher de interromper uma gravidez. Cito Daniel Maguire, formado em Roma, professor de Teologia Moral, que diz: "A anticoncepção é não somente lícita, como pode ser moralmente obrigatória. Da mesma forma, a opção por um aborto é, em muitas circunstâncias, uma opção moral para as mulheres".

Nessa intervenção, há um discurso católico em que se afirma a validez ética e moral da decisão da mulher de interromper uma gravidez, posição fundamentada na teologia e tradição da lgreja Católica. Isto, segundo Rosado e Soares, ${ }^{26}$ é o que se denomina produção de um contradiscurso que se baseia em "brechas" do discurso oficial, em posições não hegemônicas sustentadas por teólogos/as ou grupos de teólogos/as no interior da lgreja. Por outro lado, apresenta também a defasagem entre as proposições da moral sexual católica tradicional e as práticas dos fiéis nesse campo. Igualmente, contém argumentos de caráter religioso contrapostos às proposições condenatórias do aborto, que vão desde fazer explícita a dúvida sobre a posição da hierarquia da Igreja Católica até a justificação da decisão em favor da interrupção da gravidez como um comportamento moral e religiosamente aceitável.

Para finalizar essas breves reflexões sobre os debates relativos à defesa da vida, apresento a afirmação de Ennio Candotti, presidente da Sociedade Brasileira para o Progresso da Ciência-SBPC:

A Igreja Católica abandona a solidariedade humana em nome da "defesa da vida", que identifica com a fertilização do óvulo pelo espermatozóide; busca na genética amparo para definir o antes e o depois, o bem e o mal, mas omite a incessante busca de compreensão do que é vida.

\footnotetext{
${ }^{25}$ BRASIL, 1997, p. 62.

${ }^{26}$ ROSADO e SOARES, 1999. Neste mesmo texto, podem ser encontrados os argumentos da Tradição Católica relativos à possibilidade de tomar uma decisão contrária à hierarquia católica diante de uma gravidez indesejada.

${ }^{27}$ Ennio CANDOTI apud Alcilene CAVALCANTE e Dulce XAVIER, 2006, p. 57.
} 


\title{
Referências bibliográficas
}

BRASIL. Câmara dos Deputados. Departamento de Taquigrafia, Revisão e Redação. Comissão Geral. Sobre PL20/91. Sessão n. 216.3.50.0, de 25 de novembro de 1997. Brasília, 1997. p. 62.

Câmara dos Deputados. Departamento de Taquigrafia, Revisão e Redação. Audiência Pública. Sobre PEC25/95. Sessão n. 229.1.30.0, de novembro de 1995. Brasília, 1995.

CAVALCANTE, Alcilene; XAVIER, Dulce (Orgs.). Em defesa da vida: aborto e direitos humanos. São Paulo: Católicas pelo Direito de Decidir, 2006.

CFÊMEA. Direitos sexuais e reprodutivos em risco. Brasília: Cfemea, nov./dez. 2007. ano 154. COLÓN, Alice et al. "Tentativas de deslegitimação do direito ao aborto em Porto Rico". In: COSTA, Albertina de Oliveira (Org.). Direitos tardios: saúde, sexualidade e reprodução na América Latina. São Paulo: PRODIR/FCC; Ed. 34, 1997. p. 249-276.

FOCAULT, Michel. A ordem do discurso. São Paulo: Edições Loyola, 1996. 79 p. . A verdade e as formas jurídicas. Rio de Janeiro: PUC/NAU Edidora, 1971. 158 p.

PETCHESKY, Rosalind. Abortion and Women's Choice: The Atate, Sexuality, and Reproductive Freedom. Rev. ed. Boston: Northeastern University Press, 1990.

ROCHA, Maria Isabel Baltar. "A questão do aborto no Brasil: o debate no Congresso Nacional". Revista Estudos Feministas, Rio de Janeiro: CIEC/ECO/UFRJ, v. 4, n. 2, p. 381-398, 1996. RODRIGUES, Almira. Cidadania das mulheres e legis/ativo federal: novas e antigas questões em fins do século XX no Brasil. Brasília: Cfemea, 2000.

ROSADO, Maria Jose; SOARES, Regina. "Aborto: um tema em discussão na Igreja Católica". In: SCAVONE, Lucila. Género y salud reproductiva en América Latina. Costa Rica: Editora LUR, 1999. p. 257-304.

VIEIRA, Humberto Leal. Os atentados à vida e à família: um estudo das origens, estratégias e projetos. Brasília: Associação Nacional Pró-Vida e Pró-Familia, 1998.

[Recebido em março de 2008 e aceito para publicação em junho de 2008]

\begin{abstract}
Abortion: Defending Life
Abstract: This essay will analyze some of the debates around abortion in the National Congress due to the Constitutional Amendment Bill - PEC25/95, by Deputy Severino Cavalcanti (PPB/PE), where the main issue was precisely life defense. The discursive blocks that present the debate in relation to pregnancy interruption, the religious principles or biological determinism on which those debates are based, and the ways in which such discourses are maintained will be identified. Distinct understandings of life, as a result of the points used in such discourses, which are aligned with the position of the Catholic Church and the Feminist Movement - the social actors of this debate- are also discussed here.
\end{abstract}

Key Words: Abortion; Catholic Discourse; Life Defense. 